\title{
Interactive comment on "Comparison of box counting and correlation dimension methods in well logging data analysis associate with the texture of volcanic rocks" by $\mathrm{D}$. Mou and Z. W. Wang
}

\section{Anonymous Referee \#2}

Received and published: 13 September 2016

Comments on "Comparison of box-counting and correlation dimension methods in well logging data analysis associate with the texture of volcanic rocks" by D. Mou and Z. W. Wang

The authors have come a long way in making their paper easier to comprehend. The original submission did not make much sense but now the reader can follow largely what the authors have done. Nevertheless, many little problems continue to make the reading difficult. Could an English-speaking guide still provide further help? For example, further corrections or clarifications could be requested for where I put question

Printer-friendly version

Discussion paper 
marks in the following paragraph: "Well logging curves are non-regular plane curves (?), which was (?) connected with measured value (?) for each sampling points (?). NPGD To satisfy point-by-point calculation we adopt the window technique which actually was analysed for well logging curves from one window length (?).

In Fig. $3 a$, a correlation dimension is being estimated for $M=49$ and $N=7$ where $M$ is number of logging data (?) and $\mathrm{N}$ is number of data taken at the first logging data (?). The solution is written as $y=1.197^{\star} x-1.164$. This best-fitting straight line provides a poor fit to the data shown on the diagram.

In Table 2: "Texture" probably means "Type". Why is pyroclastic rock different from pyroclastic lava? What is "sink-pyroclastic" rock?

Interactive comment on Nonlin. Processes Geophys. Discuss., doi:10.5194/npg-2014-85, 2016. 